[Author's post-print of a manuscript accepted for publication in Molecular Ecology, 2018

(Early view), 00: 1-11. https://onlinelibrary.wiley.com/doi/abs/10.1111/mec.14793]

\title{
1 Asymmetric assortative mating and queen polyandry are linked to a supergene controlling ant social organization
}

Amaury Avril $^{1}$, Jessica Purcell ${ }^{2}$, Alan Brelsford ${ }^{3} \&$ Michel Chapuisat $^{1}$

${ }^{1}$ Department of Ecology and Evolution, University of Lausanne, 1015 Lausanne, Switzerland

${ }^{2}$ Department of Entomology, University of California Riverside, Riverside, CA 92521, USA

${ }^{3}$ Department of Evolution, Ecology, and Organismal Biology, University of California Riverside, Riverside, CA 92521, USA

\section{Correspondence: Michel.Chapuisat@unil.ch}

Running title: Mating system of a socially polymorphic ant

Keywords: Mating system, supergene, social organization, polymorphism, ants

\begin{abstract}
Non-recombining genomic variants underlie spectacular social polymorphisms, from bird mating systems to ant social organization. Because these "social supergenes" affect multiple phenotypic traits linked to survival and reproduction, explaining their persistence remains a substantial challenge. Here, we investigate how large non-recombining genomic variants relate to colony social organization, mating system and dispersal in the Alpine silver ant, Formica selysi. The species has colonies headed by a single queen (monogynous) and colonies headed by multiple queens (polygynous). We confirmed that a supergene with alternate haplotypes $\mathrm{Sm}$ and $\mathrm{Sp}$ - underlies this polymorphism in social structure: females from mature monogynous colonies had the $\mathrm{Sm} / \mathrm{Sm}$ genotype, while those from polygynous colonies were $\mathrm{Sm} / \mathrm{Sp}$ and $\mathrm{Sp} / \mathrm{Sp}$. Queens heading monogynous colonies were exclusively mated with Sm males. In contrast, queens heading polygynous colonies were mated with $\mathrm{Sp}$ males and $\mathrm{Sm}$ males. Sm males, which are only produced by monogynous colonies, accounted for $22.9 \%$ of the matings with queens from mature polygynous colonies. This asymmetry between social forms in the degree of assortative mating generates unidirectional male-mediated gene flow from the monogynous to the polygynous social form. Biased gene flow was confirmed by a significantly higher number of private alleles in the polygynous social form. Moreover, heterozygous queens were three times as likely as homozygous queens to be multiply mated. This study reveals that the supergene variants jointly affect social organization and multiple components of the mating system that alter the transmission of the variants and thus influence the dynamics of the system.
\end{abstract}




\section{Introduction}

Supergenes are clusters of tightly linked loci controlling complex phenotypes (Dobzhansky, 1970; Schwander, Libbrecht, \& Keller, 2014; Thompson \& Jiggins, 2014). They underlie some of the most spectacular polymorphisms in nature, including sexes (Charlesworth, 2016), mimetic forms in butterflies (Joron et al., 2011), mating tactics in birds (Küpper et al., 2016; Tuttle et al., 2016) and social organization in ants (Wang et al., 2013; Purcell, Brelsford, Wurm, Perrin, \& Chapuisat, 2014). Large non-recombining supergene variants are typically associated with differences in survival and coordinated changes in multiple morphological, physiological and behavioral traits (Schwander et al., 2014; Tuttle et al., 2016; Chouteau, Llaurens, PironPrunier, \& Joron, 2017). Because supergenes typically influence their own transmission in complex ways, understanding which mechanisms contribute to the maintenance of polymorphism is challenging (Llaurens, Whibley, \& Joron, 2017). Fundamental mechanisms stabilizing genetic polymorphisms include disassortative mating, heterozygote advantage and spatially variable selection coupled with gene flow.

The recent discovery that convergent supergenes influence colony social organization in two ant species provides a novel opportunity to investigate how supergenes contribute to intraspecific phenotypic diversity (Wang et al., 2013; Libbrecht \& Kronauer, 2014; Purcell et al., 2014). These large non-recombining variants control whether one or multiple queens reproduce within each colony. Variation in queen number shapes the degree of within-group relatedness and thus influences the inclusive fitness of helpers (Hamilton, 1964; Crozier \& Pamilo, 1996; Ross, 2001; Bourke, 2011). Given the central importance of kinship for social evolution, what causes variation in the number of queens reproducing in each colony has been a long-standing puzzle for evolutionary biologists (Hölldobler \& Wilson, 1977; Bourke \& Franks, 1995; Keller, 1995; Ross, 2001).

One solution to this puzzle is that the transition from one to multiple breeders per group may be coupled with a reduction in dispersal, thereby reducing the erosion of within-group relatedness (Nonacs, 1988; Bourke \& Franks, 1995; Ross, 2001). A recent model shows that social polymorphism readily emerges through linkage of loci involved in social behavior and dispersal, pointing to the possibility that supergenes control both traits (Mullon, Keller, \& Lehmann, 2018). So far, the coupling of social organization and dispersal within a supergene has not been directly investigated in an empirical system.

Across ant species, variation in social organization frequently correlates with shifts in dispersal and mating strategies (Bourke \& Franks, 1995; Ross, 2001). In species forming polygynous (= multiple-queen) colonies, queens often mate nearby or within their natal nest and disperse on foot and with nestmate workers to establish new nests in the vicinity (Keller, 1995; Crozier \& Pamilo, 1996; Chapuisat, Goudet, \& Keller, 1997). In contrast, in species forming monogynous (= single-queen) colonies, queens usually disperse on the wing, mate in swarms away from their natal nest, establish an incipient colony and produce their first workers independently (Timmermans, Grumiau, Hefetz, \& Aron, 2010; Jowers et al., 2013). In line with a shift in dispersal strategies, polygynous populations generally show higher levels of genetic differentiation among populations, compared to monogynous populations (reviewed in Pamilo, Gertsch, Thorén, \& Seppä, 1997; Sundström, Seppä, \& Pamilo, 2005). Whether parallel differences in dispersal and mating strategies occur between monogynous and polygynous colonies belonging to the same population deserves further investigation. A polymorphic 
population also provides an opportunity to investigate whether social organization and dispersal covary with alternative variants at a supergene.

In the Alpine silver ant, Formica selysi, social organization is associated with a polymorphic supergene that is $14.1 \mathrm{Mbp}$ long and contains 664 coding genes (Purcell et al., 2014; Avril, Tran, Brelsford, \& Chapuisat, unpublished results). The supergene has two large nonrecombining haplotypes, $\mathrm{Sm}$ and $\mathrm{Sp}$, which are highly differentiated both in nucleotide sequence and gene order. The haplotypes differ by multiple inversions (Brelsford, Purcell, \& Chapuisat, unpublished results), but it is not yet clear whether inversions are a cause or consequence of the arrest of recombination (Sun, Svedberg, Hiltunen, Corcoran, \& Johannesson, 2017). Like in other Hymenoptera the females are diploid and the males haploid. Monogynous colonies produce diploid workers and gynes (winged females destined to become queens) that all have the $\mathrm{Sm} / \mathrm{Sm}$ supergene genotype, along with haploid winged males carrying the Sm haplotype (Figure 1; Purcell et al., 2014; Purcell et al., 2016). In contrast, polygynous colonies produce $\mathrm{Sm} / \mathrm{Sp}$ and $\mathrm{Sp} / \mathrm{Sp}$ workers and gynes, along with winged males carrying exclusively Sp (Figure 1; Purcell et al., 2014; Purcell et al., 2016). The absence of Sm winged males produced by polygynous colonies suggests that the Sp haplotype is a selfish genetic element favoring its own transmission over the one of the alternative haplotype. Eggs from heterozygous queens that did not inherit $\mathrm{Sp}$ failed to hatch, indicating that $\mathrm{Sp}$ is a maternaleffect killer (Avril, Purcell, Béniguel, \& Chapuisat, unpublished results). The unusual genotypic distribution of the supergene across social forms raises multiple questions. Do queens only mate with males originating from the same social form or is there some degree of nonassortative mating? What is the pattern of gene flow between social forms? What prevents the driving haplotype Sp from going to fixation?

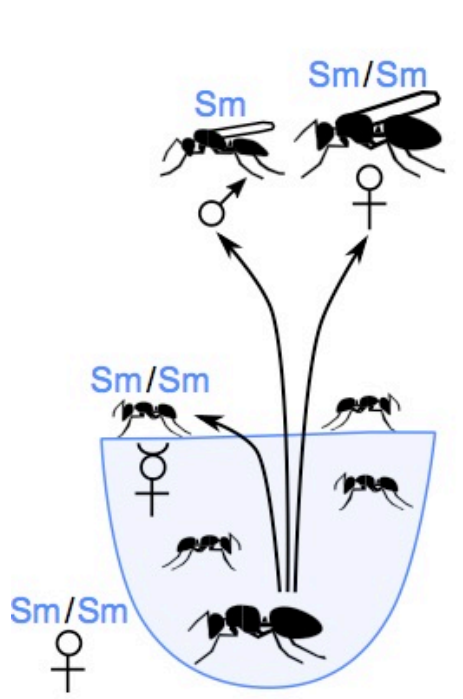

Monogynous colony

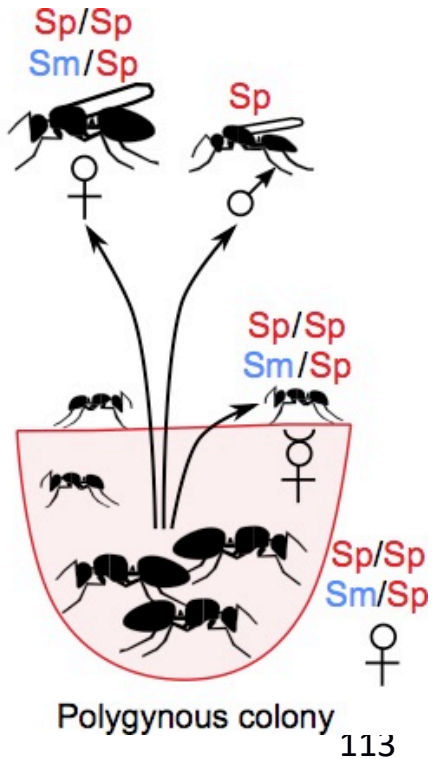

Figure 1. Genetic system underlying variation in social organization in the Alpine silver ant, F. selysi. Queens and workers are diploid females, males are haploid. Sm and Sp indicate alternative non-recombining variants (i.e., haplotypes) at a supergene associated with colony social structure. In short, workers and queens in mature polygynous colonies have one or two copies of the Sp haplotype, while workers and queens in mature monogynous colonies lack Sp. Indeed, females established in mature monogynous colonies have the supergene genotype $\mathrm{Sm} / \mathrm{Sm}$.

Monogynous colonies produce Sm/Sm workers and gynes (winged females destined to become queens), along with Sm males. Females established in mature polygynous colonies have the supergene genotypes $\mathrm{Sm} / \mathrm{Sp}$ and $\mathrm{Sp} / \mathrm{Sp}$. Polygynous colonies (= groups headed by $\mathrm{Sm} / \mathrm{Sp}$ and $S p / S p$ queens) produce $S m / S p$ and $S p / S p$ workers and gynes, along with Sp males. The absence of Sm males and $\mathrm{Sm} / \mathrm{Sm}$ females in brood produced by polygynous colonies indicates that Sp is a transmission ratio distorter and raises the question, do Sm/Sp queens mate with Sm males? 
Field observations indicate that queens and males of both social forms fly away from their natal colony and mate on top of small trees located nearby (Chapuisat, Bocherens, \& Rosset, 2004; Rosset \& Chapuisat, 2006, 2007). Whether queens and males from polygynous colonies also mate within their natal colony as an alternative strategy is presently unknown. The genetic structure at microsatellite markers did not reveal marked differences between social forms in mating or dispersal (Chapuisat et al., 2004; Purcell \& Chapuisat, 2013). Moreover, the absence of differentiation between the monogynous and polygynous social forms at both microsatellites and SNPs located outside of the supergene suggests that the social forms are not reproductively isolated (Chapuisat et al., 2004; Purcell \& Chapuisat, 2013; Purcell et al., 2014).

Here, we investigate how the supergene variants relate to colony social organization, mating system and dispersal in the Alpine silver ant. We use genomic data from offspring of isolated queens to examine whether differences in mating and dispersal of queens and males from each social form affect the transmission of alternative variants of the supergene. We pursue three main goals. First, we quantify the degree of assortative mating with respect to social origin. In particular, we examine whether queens heading mature monogynous and polygynous colonies, respectively, mated with males from the same or the alternative social origin. Second, we investigate whether queens and males of each social origin differ in their propensity to mate locally, causing differences in patterns of isolation by distance. Finally, we compare the frequency of private alleles and use Bayesian inference to assess gene flow asymmetries between social forms. These results will reveal if some degree of non-assortative mating or unusual patterns of gene flow affect the dynamics of this "social" supergene.

\section{Materials and methods}

\section{Sampling and genotyping strategy}

The Alpine silver ant Formica selysi is a socially polymorphic species that inhabits large valleys in the Alps and the Pyrenees (Chapuisat et al., 2004; Purcell, Pellissier, \& Chapuisat, 2015). The study population is located in central Valais, Switzerland (Finges; 7 36 '30" E, 4 $18^{\prime} 30^{\prime \prime}$ $\mathrm{N}$, altitude: $565 \mathrm{~m}$; Figure S1). The social organization (monogynous or polygynous) of colonies included in the present study had been previously determined by genotyping nestmate workers at microsatellite markers (Purcell \& Chapuisat, 2013). It was further confirmed by counting queens during sampling and analyzing single nucleotide polymorphisms (SNPs) located outside and within the supergene (see below).

To infer the genotypes of queens and their mates, we genotyped offspring of single queens (= progenies) and reconstructed the parental genotypes. This strategy was chosen to circumvent the difficulty and destructive nature of sampling mature queens from monogynous colonies. Therefore, workers from monogynous colonies were sampled from the field. A similar genotyping of progeny was applied to queens from polygynous colonies in order to obtain comparable data on mating frequency and mate genotypes for both social forms. We thus analyzed workers and eggs from queens sampled in polygynous field colonies and reared singly in laboratory colonies (Figure S2).

The sampling and genotyping strategy combined RAD-seq genotyping of worker progenies from single (isolated) queens and PCR-RFLP assay of queens, mates and eggs (Figure S2; Table S1). Progenies from monogynous queens consisted of four workers sampled from each of 63 monogynous colonies (Figure S1; Table S1). Progenies from polygynous queens were obtained 
by isolating 142 wingless reproductive queens sampled from 51 polygynous colonies (Figure S1; Table S1). To minimize the impact of sampling, we left at least two observed queens in each polygynous colony. Each sampled queen was placed individually in a small plastic box $(15 \times 13 \times 6 \mathrm{~cm})$, with 20 adult workers from the same parent colony. The ants were provided with a nest site, water and ad libitum ant food (Meunier \& Chapuisat, 2009). Brood production was monitored daily. Four callow (young) workers per queen were collected for 120 queens originating from 37 polygynous colonies.

We obtained RAD-seq data for four workers per queen coming from 63 monogynous and 37 polygynous colonies, respectively (Table S1; Figure S2). The RAD-seq data were used to reconstruct the genotypes of the live queens and their mates at SNPs outside of the supergene and in the supergene (Table S1). The SNPs outside of the supergene were used to determine queen mating frequency and for all population genetic analyses. The supergene genotype was used to determine the social origin of the queens and their male mates (Table S1).

In addition to the four callow workers, we collected at least eight eggs per queen for all queens from polygynous colonies (Figure S2). At the end of the experiment, we dissected the queens and extracted the sperm contained in their spermathecae (Chapuisat, 1998). The supergene genotypes of queens, sperm and eggs from polygynous colonies were determined with a PCRRFLP assay that discriminates three SNPs diagnostic for alternative haplotypes of the supergene (Purcell et al., 2014). These RFLP data were used to confirm the supergene genotypes of queens and mates inferred from RAD-seq data and to supplement the mating pattern data (Table S1).

DNA was extracted from the head of queens and from the head and thorax of workers with Qiagen Blood and Tissue extraction kit (Qiagen, Hombrechtikon, Switzerland). DNA from eggs and sperm was extracted with a salting-out procedure (Miller, Dykes, \& Polesky, 1988).

\section{Genotyping-by-sequencing}

We used a genotyping-by-sequencing (RAD-seq) approach to identify SNPs in workers (Brelsford, Dufresnes, \& Perrin, 2016; Purcell et al., 2016). The DNA was digested with restriction enzymes MseI and SbfI. This combination of enzymes produced a low density of SNP markers, which allowed us to multiplex the 732 workers on a single lane of Illumina HiSeq 2500 with an average coverage of 197 reads per locus per individual. The sequencing was performed at the Lausanne Genomic Technology Facility in Lausanne, Switzerland.

The genetic data were processed with the software pipeline Stacks v1.46 (Catchen, Hohenlohe, Bassham, Amores, \& Cresko, 2013). The raw reads were demultiplexed using the process_radtags module, and 22 individuals that had low numbers of reads $(<10,000)$ were removed from the dataset. Reads were aligned to a reference genome with BWA v0.7.13 (H. Li $\&$ Durbin, 2009). SNPs and genotypes were called with the ref_map module of Stacks. To avoid bias due to linkage disequilibrium between adjacent markers, one SNP per RAD tag was randomly selected, using VCFtools v0.1.14 (Danecek et al., 2011). The SNPs in the supergene, which are linked, were retained but were analyzed separately from the ones outside of the supergene. Genotypes with a quality score below 20 were treated as missing data. SNPs with a minor allele frequency below 0.01 or missing for more than $20 \%$ of the individuals were removed from the dataset. The final dataset included 271 SNPs, of which 25 were in the supergene and 246 in the rest of the genome. 
For each sibship (progenies from singly mated queens), the genotypes of the queen and her male mate were reconstructed from RAD-seq data using the computer program COLONY v2.0.6.1 (Jones \& Wang, 2010). For population genomic analyses we conserved the 246 generated SNPs located outside of the supergene and excluded the 25 SNPs in the supergene. Parental genotypes at given SNPs for which the posterior probability was below 0.8 were considered missing values. For multiply mated queens, the maternal and paternal genotypes could not be unambiguously reconstructed. These queens and their male mates were excluded from population genetic analyses on sex-specific dispersal (section 2 below). In total, we reconstructed the genotypes at SNPs outside of the supergene for 157 singly mated queens and their mates.

\section{Genetic data analyses}

\section{Social structure, supergene genotypes, mating pattern and queen mating frequency}

The social structure of each colony had been previously inferred from microsatellite genotypes of worker nestmates (Chapuisat et al., 2004; Purcell \& Chapuisat, 2013). It was confirmed by direct observation of queens in the field (polygynous colonies) and by measuring the relatedness among nestmates (monogynous colonies). The supergene genotype of each queen and respective male mate(s) was inferred from the supergene genotype of the worker progeny (25 SNPs in the supergene obtained by RAD-seq; Table S1). For queens and mates from polygynous colonies, the supergene genotypes were further assessed with a PCR-RFLP assay of queens, sperm and eggs (Purcell et al., 2014; Table S1).

We calculated the maximum likelihood relatedness among workers from single queens (progenies) with the algorithm of Huang et al. (2015), implemented in the software PolyRelatedness v1.6. To obtain unbiased estimate of relatedness, we used RAD-seq generated SNPs located outside of the supergene. We estimated background allele frequencies with colonies being weighted equally. Using these frequencies, we simulated 1,000 datasets consisting of full-sibs (i.e. offspring from single-mated queens), calculated their relatedness and estimated the $95 \%$ confidence interval around 0.75 , the expected relatedness for full-sibs in haplo-diploids. In complement to the relatedness analysis, we inferred the pedigree relationships between sampled workers using the maximum likelihood approach implemented in the program COLONY v2.0.6.1 (Jones \& Wang, 2010). This method identifies full-sib and half-sib groups. Consensus pedigree relationships were obtained from five iterations, with a genotyping error rate set up at 0.01 per locus.

Queens were inferred to be singly mated when their worker progeny (i) had a relatedness not significantly different from 0.75 ; and (ii) belonged to a full-sib group in the pedigree reconstruction. Conversely, queens were assessed to be multiply mated when their worker progeny had a relatedness significantly lower than 0.75 and belonged to a half-sib group. One doubly mated queen had progeny with relatedness estimate not significantly different from 0.75. Due to the small number of offspring genotyped, the number of mates per queen and the proportion of multiply-mated queens are minimum estimates (Boomsma \& Ratnieks, 1996). With four offspring, there is a 0.125 probability of not sampling a patriline when a queen had mated with two equally contributing males. However, because we genotyped the same number 
of offspring per queen, we can still compare the relative mating frequencies of queens with alternative social genotypes.

\section{Dispersal of queens and males}

To get insight into the mating pattern we estimated the relatedness of the male mate to the queen with the computer program PolyRelatedness v1.6. To test whether the male mate to queen relatedness differs between social forms, we used a linear mixed model with the mate to queen relatedness as response variable, queen and male social origin as fixed factors and the colonies from which queens were sampled as a random factor. The model was built with the 'Ime4' $\mathrm{R}$ package (Bates, Mächler, Bolker, \& Walker, 2015).

We estimated the relatedness among nestmate queens, among male mates of nestmate queens and among progenies of nestmate queens with the computer program PolyRelatedness v1.6. To estimate background allele frequencies, colonies were weighted equally. We simulated 1,000 datasets of unrelated individuals and computed the $95 \%$ confidence intervals around the relatedness of zero corresponding to this null hypothesis.

Dispersal of queens and males was inferred by computing isolation by distance. The kinship coefficient between pairs of individuals was regressed against the natural logarithm of distance. We used Loiselle kinship coefficient because it is not affected by the ploidy of individuals, thereby allowing us to compare the magnitude of isolation by distance between sexes (Loiselle, Sork, Nason, \& Graham, 1995; Hardy, Pearcy, \& Aron, 2008). Regression was restricted to a maximal distance of 900 meters to ensure that the computation was performed on a similar scale for all comparisons. Correlation between the genetic and geographic matrices was tested with a Mantel test with 10,000 permutations.

\section{Gene flow between social forms}

The amount of genetic differentiation between social forms was estimated using hierarchical $F$ statistics, with workers nested in sibships, sibships nested in colonies, and colonies nested in social forms. Calculation was performed with the Hierfstat R package v0.04-22 (Goudet, 2005). Confidence intervals were obtained from 10,000 bootstrap resamples of loci.

We estimated the number of private alleles in workers from monogynous and polygynous colonies, respectively (Slatkin, 1985). To control for the effects of unequal samples sizes and hierarchical sampling, we bootstrap resampled the same number of workers in the monogynous and polygynous social form, using only one individual per colony (Kalinowski, 2004). We computed the number of private alleles in each social form with the R package 'poppr', based on 10,000 bootstrap resamples (Kamvar, Tabima, \& Grunwald, 2014). We used a permutation test to evaluate whether the number of private alleles differed significantly between social forms.

To estimate the number of immigrants per generation between social forms, we used the Bayesian approach implemented in the computer program MIGRATE v3.6.11 (Beerli \& Palczewski, 2010). MIGRATE uses coalescent theory to estimate population genetic parameters under the assumption of mutation-migration-drift equilibrium. The number of immigrants per generation is calculated as the product between the mutation-scaled effective population size within a focal social form and the mutation-scaled migration rate from the focal 
social form to the other social form. We ran MIGRATE with 20,000 burnin and 1,000,000 iterations.

\section{Results}

1. Social structure, supergene genotypes, mating pattern and queen mating frequency

The presence of a single reproducing queen in monogynous colonies was confirmed by the relatedness among nestmate workers being close to 0.75 and by pedigrees consistent with a single queen (Table S1). The presence of multiple queens in polygynous colonies was demonstrated by direct sampling and observation of multiple wingless reproductive queens. Social organization was perfectly associated with the genotypes of queens at the supergene: all queens from monogynous colonies were $\mathrm{Sm} / \mathrm{Sm}$, and all queens from polygynous colonies had at least one $\mathrm{Sp}$ haplotype, $51.3 \%$ being $\mathrm{Sm} / \mathrm{Sp}$ and the rest $\mathrm{Sp} / \mathrm{Sp}$ (Figure 2; Figure 3; Table $\mathrm{S} 1)$.

Queens heading mature monogynous colonies were invariably mated with Sm males (Figure 2; Figure 3; Table S1). In contrast, queens in polygynous colonies were mated with $\mathrm{Sm}$ and $\mathrm{Sp}$ males, with a relative contribution of Sm males totaling 22.9\% (Figure 2; Figure 3; Table S1). The proportion of mating with $\mathrm{Sm}$ versus $\mathrm{Sp}$ males did not differ significantly between $\mathrm{Sp} / \mathrm{Sp}$ and $\mathrm{Sm} / \mathrm{Sp}$ queens (Figure 2; Fisher exact test, $\mathrm{p}=1$ ).

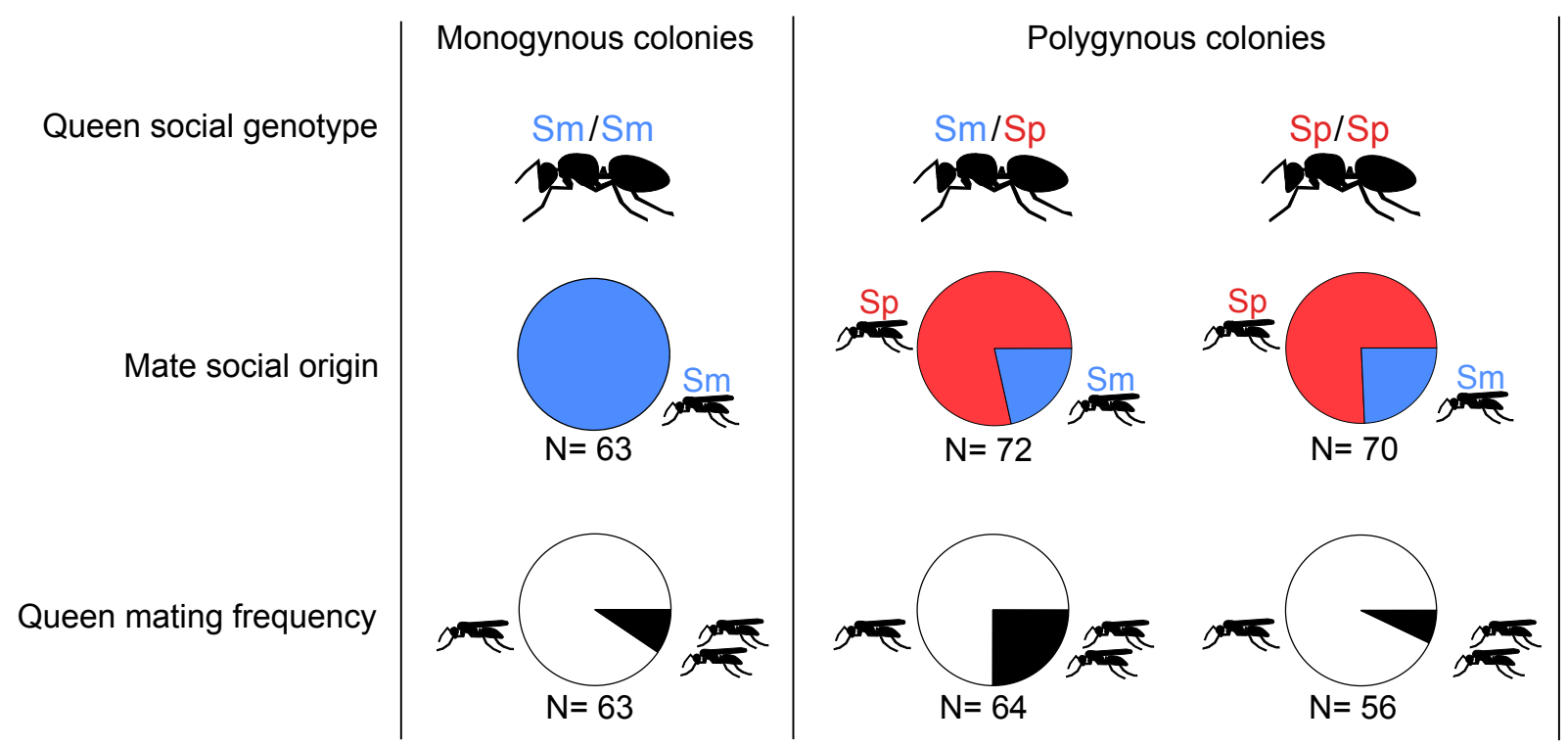

Figure 2. Social genotypes of queens and their male mates heading mature field colonies. Blue and red pie charts indicate the proportion of mating with Sm males (blue) and Sp males (red), respectively. White and black pie charts indicate the proportion of single mating (white) and multiple mating (black) by queens. $N$ is the number of queens. See Table S1 for details. 


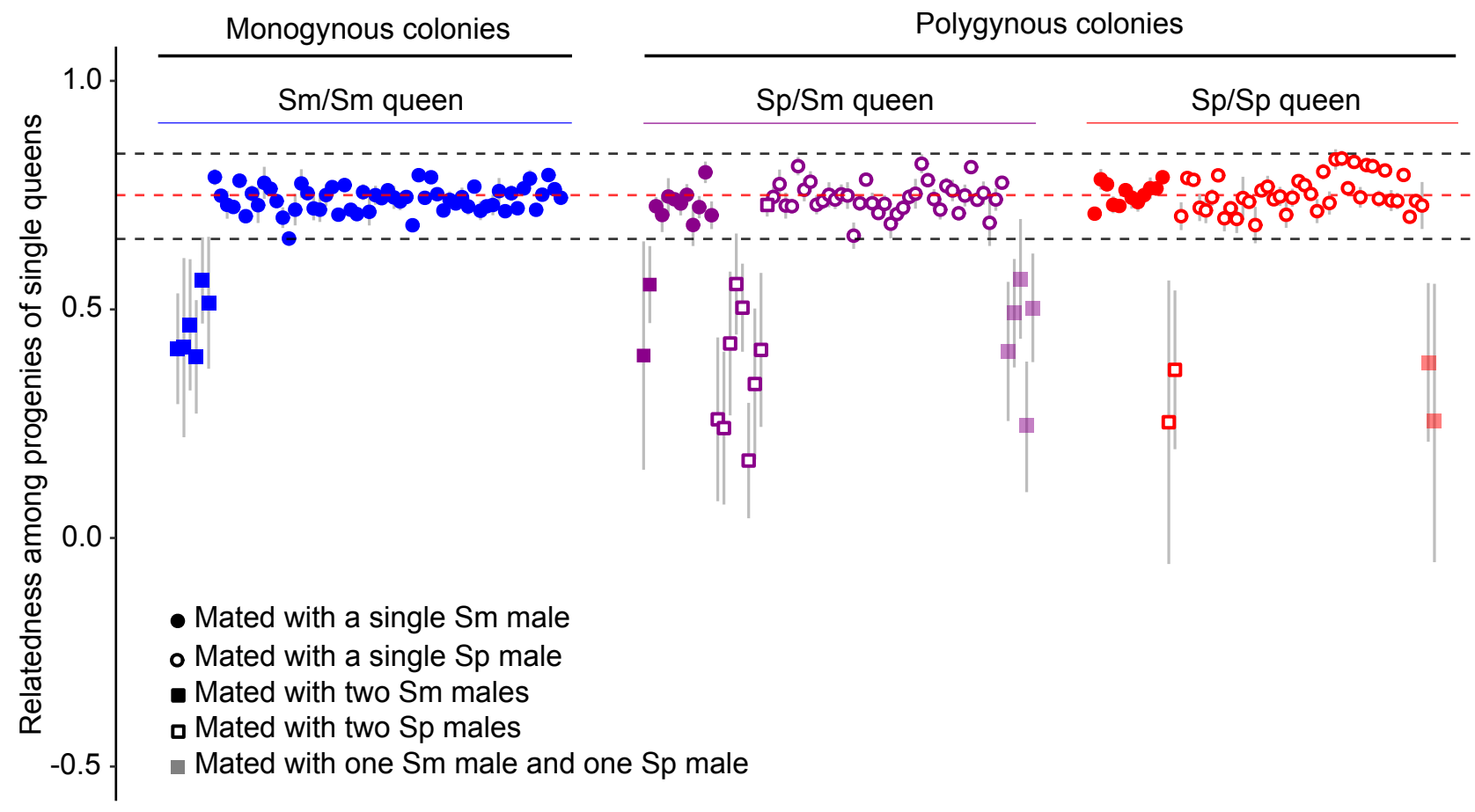

Figure 3. Social structure, supergene genotype and queen mating frequency. The y axis shows the relatedness (mean $\pm S E$ ) among progenies of single queens originating from monogynous colonies (left side of graph) and polygynous colonies (right side of graph), respectively. Red and black dotted lines indicate the mean and 95\% confidence interval of the expected relatedness among progenies of a singly mated queen. Blue, purple and red symbols represent progenies of $\mathrm{Sm} / \mathrm{Sm}$ queens, $\mathrm{Sp} / \mathrm{Sm}$ queens, and $\mathrm{Sp} / \mathrm{Sp}$ queens, respectively. Filled and open symbols represent progenies of queens mated with $\mathrm{Sm}$ and $\mathrm{Sp}$ males, respectively. Shaded symbols represent progenies of queens mated with one Sp and one Sm male. Circles stand for progenies of singly mated queen. Squares indicate progenies of multiply mated queens.

Most queens were singly mated (Figure 2; Figure 3; Table S1). Yet, at least $16.7 \%$ of the queens in polygynous colonies and $9.5 \%$ of the queens in monogynous colonies were mated with two males (Figure 2; Fisher exact test, $\mathrm{p}=0.26$ ). Given the small number of offspring genotyped, these observed mating frequencies are underestimates of actual mating frequencies. Notably, despite small sample size the observed mating frequency of queens in monogynous colonies is in line with previous estimates based on larger sample sizes in the same population (Chapuisat et al., 2004; Purcell \& Chapuisat, 2013). The rate of multiple mating was associated with the social genotype of the queens. Heterozygous $\mathrm{Sm} / \mathrm{Sp}$ queens were significantly more likely to be multiply mated than homozygous $\mathrm{Sp} / \mathrm{Sp}$ and $\mathrm{Sm} / \mathrm{Sm}$ queens (Figure 2; Figure 3; Fisher exact test, $\mathrm{p}=0.012$ ). 
The relatedness between queens and their male mates depended on the social origin of queens (Figure 4; Linear mixed model; $\mathrm{F}_{(2,107)}=5.80, \mathrm{p}=0.0041$ ). The relatedness of male mates to queens in polygynous colonies was significantly higher than the relatedness of male mates to queens in monogynous colonies (Figure 4). This pattern suggests that some queens from polygynous colonies mated with related $\mathrm{Sp}$ males originating from their own colony or a nearby polygynous colony, while other queens might have mated with related Sm males produced by the same monogynous colony in the neighborhood over multiple years. In contrast, queens from monogynous colonies mated with non-relatives.

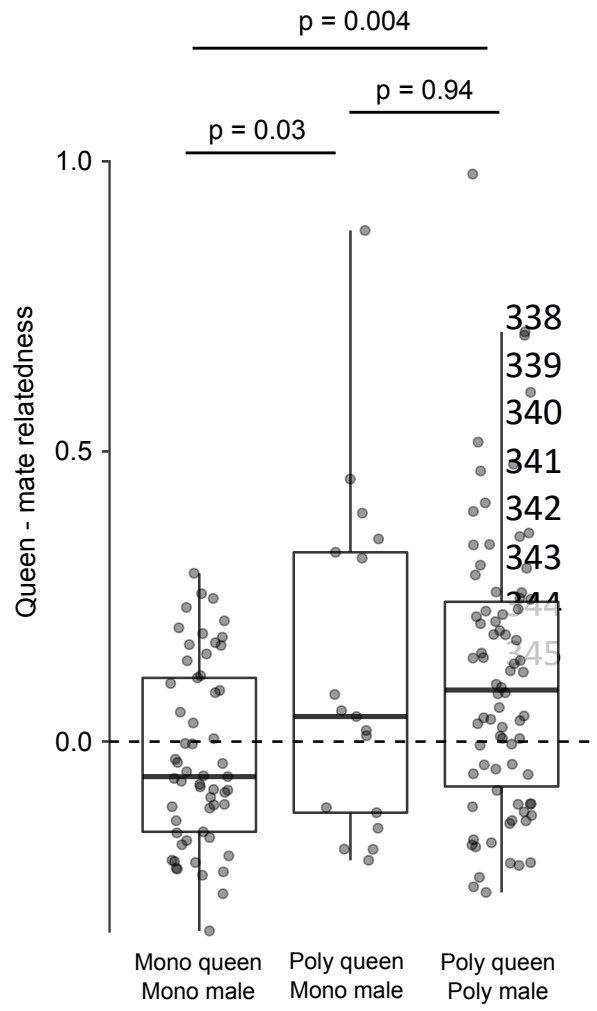

Figure 4. Relatedness of male mates to queens: mates of monogynous origin to queens in monogynous colonies (left bar), mates of monogynous origin to queens in polygynous colonies (central bar) and mates of polygynous origin to queens in polygynous colonies (right bar). Boxplots represent the lower and upper quartiles and whiskers the minimum and maximum values (in the limits of $1.5 \times$ interquartile range).

Two lines of evidence indicate that queens in polygynous colonies were related, as expected if some of these queens had stayed within or close to their natal colony. First, the relatedness among nestmate queens was significantly greater than zero $(r=0.179 \pm 0.018$; mean $\pm \mathrm{SE} ; \mathrm{p}<$ $0.05)$, while the relatedness among their mates was not $(r=0.056 \pm 0.007$; mean $\pm \mathrm{SE} ; \mathrm{p}>$ $0.05)$. Second the relatedness between progenies of queens belonging to the same polygynous colony was significantly greater than zero $(r=0.117 \pm 0.089$; mean \pm SE; $p<0.05$; Table S1).

For both social forms, patterns of isolation by distance revealed signs of restricted dispersal for queens, but not for males (Table 1). Indeed, the kinship coefficient decreased significantly with geographic distance for queens heading monogynous colonies and for queens heading polygynous colonies. In contrast, no significant isolation by distance was detected for males of monogynous origin, nor for males of polygynous origin (Table 1). 
Table 1. Isolation by distance for queens and males belonging to each social form. $\mathrm{R}^{2}$ is the correlation between kinship coefficient and geographic distance, $b$ the slope of the regression and $\mathrm{p}$ the significance of the Mantel test.

\begin{tabular}{|r|ccc|}
\cline { 2 - 4 } \multicolumn{1}{c|}{} & $\mathbf{R}^{\mathbf{2}}$ & $\mathbf{b}$ & $\mathbf{p}$ \\
\hline Monogynous social form & & & \\
Queens & -0.06 & -0.0056 & 0.011 \\
Males & -0.022 & -0.000044 & 0.11 \\
\hline Polygynous social form & & & \\
Queens & -0.048 & -0.0082 & 0.003 \\
Males & 0.022 & 0.0007 & 0.12 \\
\hline
\end{tabular}

\section{Gene flow between social forms}

There was little genetic differentiation between social forms at SNPs located outside of the supergene $\left(\mathrm{F}_{\mathrm{ST}}=0.0021,95 \%\right.$ confidence interval $\left.[0.0003,0.0039]\right)$. This absence of differentiation is in line with previous findings based on microsatellites and suggests ongoing gene flow between social forms (Chapuisat et al., 2004; Purcell \& Chapuisat, 2013). The private allele analysis was consistent with unidirectional gene flow from the monogynous to the polygynous social form. Indeed, there were significantly more private alleles in workers of the polygynous social form than in workers of the monogynous social form (Figure 5). The Bayesian estimates of migration also suggest biased gene flow, with twice as many immigrants per generation from the monogynous to the polygynous social form compared to the reverse direction ( $\mathrm{Nm}$ from the monogynous to the polygynous social form: median $=8.22,95 \%$ confidence interval $[4.39,11.7]$; $\mathrm{Nm}$ from the polygynous to the monogynous social form: median $=3.7,95 \%$ confidence interval $[1.82,5.89])$.

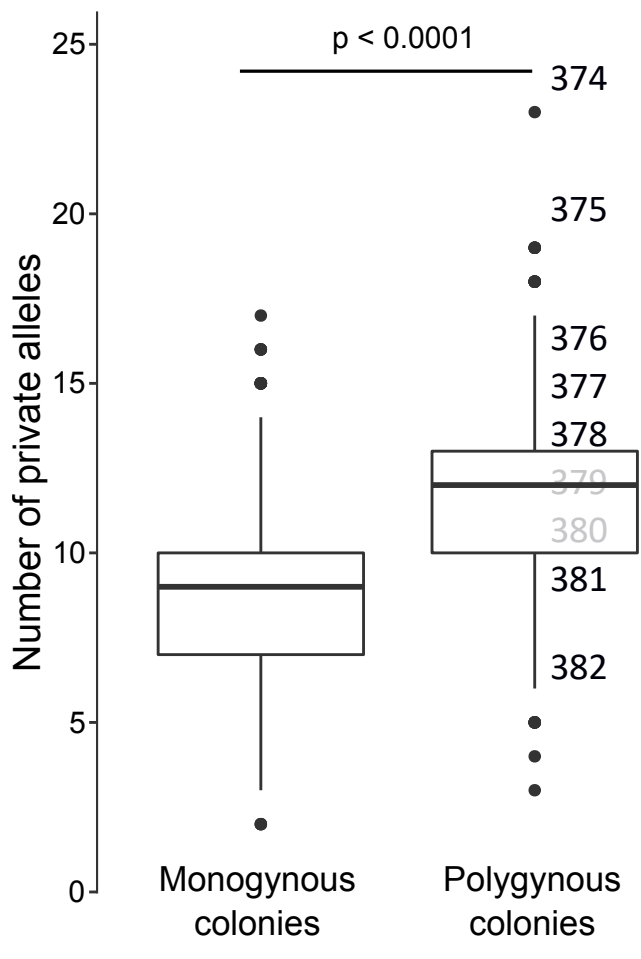

Figure 5. Number of private alleles in workers from monogynous and polygynous colonies, respectively, based on bootstrap resamples with one worker per colony. Boxplots represent the lower and upper quartiles and whiskers the minimum and maximum values (in the limits of $1.5 \times$ interquartile range). 
Genomic rearrangements associated with extended regions of suppressed recombination underlie spectacular alternative phenotypes within populations (Schwander et al., 2014; Küpper et al., 2016; Llaurens et al., 2017). Diverse mechanisms contribute to stabilize these polymorphic supergenes, generally through some form of heterozygous advantage or negative frequency-dependent selection (Llaurens et al., 2017). In many supergenes, the mutant haplotype is a recessive lethal that confers some reproductive advantage to heterozygous individuals (Wang et al., 2013; Schwander et al., 2014; Küpper et al., 2016). In other cases, disassortative mating balances the polymorphism (Li et al., 2016; Tuttle et al., 2016; Chouteau et al., 2017; Branco et al., 2018). In the Alpine silver ant, Formica selysi, a large genomic polymorphism is associated with social organization (Purcell et al., 2014). Both homozygotes are viable and the factors contributing to the maintenance of the polymorphism remain mysterious.

To gain insights into the dynamics of alternate supergene haplotypes controlling social organization, we investigated the mating system and dispersal strategies of queens and males belonging to alternative social forms of the Alpine silver ant. We combined field sampling of queens, RAD-seq genotyping of worker progenies and PCR-RFLP assays discriminating alternative haplotypes of the supergene in queens, sperm and eggs. Together, these data confirmed that colony social structure - being headed by one or by multiple reproductive queens - was perfectly associated with alternative genotypes at a large supergene (Purcell et al., 2014). The Sp haplotype was present in all queens heading multiple-queen colonies, with $\mathrm{Sp} / \mathrm{Sp}$ and $\mathrm{Sm} / \mathrm{Sp}$ queens in similar proportions, while all queens heading single-queen colonies were $\mathrm{Sm} / \mathrm{Sm}$. This unusual genotypic distribution in mature colonies prompted us to further investigate the mating system, with a focus on whether mating in polygynous colonies is assortative or disassortative with respect to the supergene haplotype.

The genotypes of queens and their mates revealed an asymmetry between social forms in the frequency of non-assortative mating. Queens heading polygynous colonies were mated with $\mathrm{Sp}$ males and Sm males, with the latter contributing to $22.9 \%$ of the mating (calculated weighting all queens equally, independently on whether they had mated singly or multiply). This is an intriguing mating pattern, because polygynous colonies do not produce Sm males (Figure 1; Purcell et al., 2014 and unpublished data: 94 males from 21 polygynous colonies were all Sp). We conclude that a fraction of polygynous queens mate with $\mathrm{Sm}$ males originating from monogynous colonies. In contrast, all queens heading mature monogynous colonies were mated with Sm males. We did not detect even a single case of non-assortative mating in monogynous colonies, i.e. $\mathrm{Sm} / \mathrm{Sm}$ queen mated with $\mathrm{Sp}$ male. The cause of this absence remains to be investigated. Possible mechanisms include mate choice, mate availability, underdominance or genetic incompatibilities. Alternatively, crosses between $\mathrm{Sm} / \mathrm{Sm}$ queens and $\mathrm{Sp}$ males may be transient, the incipient colony being converted into a polygynous colony headed by multiple $\mathrm{Sm} / \mathrm{Sp}$ daughter queens.

The asymmetric pattern of mating between social forms is expected to result in unidirectional male-mediated gene flow from the monogynous to the polygynous social form. In line with this prediction, we detected more private alleles in the polygynous social form than in the monogynous social form. Moreover, the Bayesian estimate of the number of immigrants per generation was twice as high from the monogynous to the polygynous social form than in the other direction. Genetic differentiation between social forms was close to zero at markers 
located outside of the supergene, indicating that gene flow is strong enough to homogenize allelic frequencies between social forms, as already reported in previous studies of the same population (Chapuisat et al., 2004; Purcell \& Chapuisat, 2013; Purcell et al., 2014).

Complete assortative mating in the monogynous social form coupled with partial assortative mating in the polygynous social form generates a mating advantage to Sm males, which runs counter to the drive favoring the Sp haplotype (maternal-effect killing; Avril, Purcell, Béniguel, $\&$ Chapuisat, unpublished results). Whether the combined selective forces maintain a polymorphism, and the conditions under which they do so, requires modeling. Preliminary results suggest that additional selective forces are needed to balance the polymorphism, as mating biases against $\mathrm{Sp}$ when rare and transmission ratio distortion against $\mathrm{Sm}$ when rare hinder polymorphism (Ghaseminejad, Chapuisat, \& Otto, unpublished result). A similar pattern of male-mediated unidirectional gene flow from monogynous to polygynous populations has been documented in Solenopsis invicta, another ant species where social organization is determined by a supergene (Ross \& Keller, 1995; Shoemaker \& Ross, 1996; Wang et al., 2013). Interestingly, in S. invicta the haplotype causing polygyny favors its own transmission through a green beard effect (Keller \& Ross, 1998). One difference between the two systems is that in $F$. selysi biased gene flow occurs among colonies belonging to the same local population.

$F$. selysi queens with alternative genotypes at the supergene differed in their rate of polyandry. Specifically, the occurrence frequency of multiple mating was three times higher for $\mathrm{Sm} / \mathrm{Sp}$ queens than for homozygous queens. Mating with a single Sm male is detrimental for heterozygous queens, because the $\mathrm{Sp}$ haplotype is a maternal-effect killer causing developmental arrest of their Sm/Sm brood (Avril, Purcell, Béniguel, \& Chapuisat, unpublished results). Mating with multiple males might be a form of bet-hedging to mitigate the costs induced by the driving haplotype, as suggested for the $t$-locus in mice (Sutter \& Lindholm, 2015). More generally, polyandry occurs in response to the low fertility of males carrying the driving haplotypes in multiple systems, including fire ants (Lawson, Vander Meer, \& Shoemaker, 2012; Wedell, 2013; Holman, Price, Wedell, \& Kokko, 2015). Low fertility of Sp males coupled with the cost of maternal-effect killing may contribute to the elevated rate of polyandry in heterozygous queens. Whether heterozygous queens are more attractive than homozygous queens and whether higher mating frequency provides a fitness advantage to heterozygous queens remain to be investigated.

Three complementary methods to infer dispersal propensities of males and queens of monogynous and polygynous origin provided limited support for the predicted link between supergene variant, social structure and dispersal (Mullon et al., 2018). In contrast to the model prediction, genetic data from queens and their mates did not reveal major differences in dispersal between alternative social forms. Queens of both social forms showed signs of isolation by distance, consistent with restricted dispersal. Isolation by distance was lower and not significant for males, suggesting that males of both social forms are better dispersers than queens. Such a difference between sexes has already been documented in ants - males can disperse long distances on the wing and any post-mating dispersal by queens carrying sperm stored in their spermathecae will further contribute to disperse male genes (Sundström, Keller, \& Chapuisat, 2003; Holzer, Keller, \& Chapuisat, 2009). Yet, in line with the expectation that queens of polygynous origin (bearing the $\mathrm{Sp}$ variant) should be more philopatric than queens of monogynous origin (lacking the Sp variant), two lines of evidence suggest that queens from polygynous colonies tend to mate nearby and often stay in their natal colony. First, the relatedness between queens and their mates was higher for queens in polygynous colonies than 
for queens in monogynous colonies. Second, nestmate queens in polygynous colonies were significantly related. Local mating and establishment in natal colony appears to be common to many polygynous ant species and is associated with large colony size, long colony lifespan and colony propagation by budding, a process whereby queens and workers depart on foot to jointly establish a new colony nearby (Nonacs, 1988; Bourke \& Franks, 1995; Keller, 1995; Rosset \& Chapuisat, 2007). This alternative dispersal strategy likely contributes to the success and persistence of the polygynous social organization.

\section{Conclusion}

Large non-recombining genomic variants underlying alternative social systems typically affect multiple behavioral traits, including cooperative behavior, aggression and mate choice (e.g. Tuttle et al., 2016). They can influence their own transmission in multiple ways and have complex effects across multiple levels of biological organization. Here we showed that the supergene controlling social organization in the Alpine silver ant is linked to major differences in the mating system. First, heterozygous queens were three times as likely as homozygous queens to be multiply mated. Second, males and females of alternative social forms differed in their propensity to mate with the opposing social form. Specifically, males of monogynous origin mated with both types of queens, while queens of polygynous origin mated with both types of males. The asymmetry in the amount of assortative mating provides a mating advantage to males of monogynous origin, which runs counter to the transmission ratio distortion that favors the haplotype underlying polygynous social structure. These opposing forces will greatly affect the dynamics of the genetic polymorphism controlling ant social organization.

\section{Acknowledgements}

We thank Benjamin Freeman, Alireza Ghaseminejad, Sarah P. Otto, Jonathan Rolland, Marius Roesti, Dolph Schluter, Ken Thompson, the editor Louis Bernatchez and two anonymous reviewers for comments on the manuscript. M.C. thanks Dolph Schluter for hosting him during his sabbatical at the University of British Columbia. The computations were performed at the Vital-IT center for high-performance computing of the Swiss Institute of Bioinformatics. Funding was provided by the Swiss National Science Foundation grants 31003A-146641 and 31003A-173189 to M.C., the University of Lausanne and the Fondation Herbette UNIL.

\section{Data accessibility}

Demultiplexed genotyping-by-sequencing reads have been deposited in the NCBI Sequence Read Archive under the accession number SRP150340. Table S1 in supporting information describes all samples, genetic analyses and social genotypes of queens heading monogynous or polygynous colonies, their worker progeny, eggs and male mates, respectively.

\section{Author contribution}

A.A. J.P. and M.C. designed the study. A.A. performed the experiments and laboratory analyses. A.A. analyzed the data with input from all authors. A.A. and M.C. wrote the manuscript with input from J.P. and A.B. 


\section{References}

Bates, D., Mächler, M., Bolker, B., \& Walker, S. (2015). Fitting linear mixed-effects models using lme4. Journal of Statistical Software, 67, 1-48. doi:10.18637/jss.v067.i01

Beerli, P., \& Palczewski, M. (2010). Unified framework to evaluate panmixia and migration direction among multiple sampling locations. Genetics, 185, 313-326. doi:10.1534/genetics.109.112532

Boomsma, J. J., \& Ratnieks, F. L. W. (1996). Paternity in eusocial Hymenoptera. Philosophical Transactions of the Royal Society B-Biological Sciences, 351, 947-975.

Bourke, A. F. G. (2011). Principles of social evolution. Oxford: Oxford University Press.

Bourke, A. F. G., \& Franks, N. R. (1995). Social evolution in ants. Princeton, NJ: Princeton University Press.

Branco, S., Carpentier, F., de la Vega, R. C. R., Badouin, H., Snirc, A., Le Prieur, S., .. . Giraud, T. (2018). Multiple convergent supergene evolution events in mating-type chromosomes. Nature Communications, 9.

Brelsford, A., Dufresnes, C., \& Perrin, N. (2016). High-density sex-specific linkage maps of a European tree frog (Hyla arborea) identify the sex chromosome without information on offspring sex. Heredity, 116, 177-181. doi:10.1038/hdy.2015.83

Catchen, J., Hohenlohe, P. A., Bassham, S., Amores, A., \& Cresko, W. A. (2013). Stacks: an analysis tool set for population genomics. Molecular Ecology, 22, 3124-3140. doi:10.1111/mec. 12354

Chapuisat, M. (1998). Mating frequency of ant queens with alternative dispersal strategies, as revealed by microsatellite analysis of sperm. Molecular Ecology, 7, 1097-1105.

Chapuisat, M., Bocherens, S., \& Rosset, H. (2004). Variable queen number in ant colonies: no impact on queen turnover, inbreeding, and population genetic differentiation in the ant Formica selysi. Evolution, 58, 1064-1072.

Chapuisat, M., Goudet, J., \& Keller, L. (1997). Microsatellites reveal high population viscosity and limited dispersal in the ant Formica paralugubris. Evolution, 51, 475-482.

Charlesworth, D. (2016). The status of supergenes in the 21st century: recombination suppression in Batesian mimicry and sex chromosomes and other complex adaptations. Evolutionary Applications, 9, 74-90. doi:10.1111/eva.12291

Chouteau, M., Llaurens, V., Piron-Prunier, F., \& Joron, M. (2017). Polymorphism at a mimicry supergene maintained by opposing frequency-dependent selection pressures. Proceedings of the National Academy of Sciences of the United States of America, 114, 8325-8329. doi:10.1073/pnas. 1702482114

Crozier, R. H., \& Pamilo, P. (1996). Evolution of social insect colonies: sex allocation and kin selection. Oxford: Oxford University Press.

Danecek, P., Auton, A., Abecasis, G., Albers, C. A., Banks, E., DePristo, M. A., .. . Durbin, R. (2011). The variant call format and VCFtools. Bioinformatics, 27, 2156-2158. doi:10.1093/bioinformatics/btr330

Dobzhansky, T. (1970). Genetics of the evolutionary process. New York, NY, USA: Columbia University Press. 
Goudet, J. (2005). HIERFSTAT, a package for R to compute and test hierarchical $F$-statistics. Molecular Ecology Notes, 5, 184-186.

Hamilton, W. D. (1964). The genetical evolution of social behaviour. Journal of Theoretical Biology, 7, 1-52.

Hardy, O. J., Pearcy, M., \& Aron, S. (2008). Small-scale spatial genetic structure in an ant species with sex-biased dispersal. Biological Journal of the Linnean Society, 93, 465473.

Hölldobler, B., \& Wilson, E. O. (1977). The number of queens: an important trait in ant evolution. Naturwissenschaften, 64, 8-15.

Holman, L., Price, T. A. R., Wedell, N., \& Kokko, H. (2015). Coevolutionary dynamics of polyandry and sex-linked meiotic drive. Evolution, 69, 709-720. doi:10.1111/evo.12595

Holzer, B., Keller, L., \& Chapuisat, M. (2009). Genetic clusters and sex-biased gene flow in a unicolonial Formica ant. BMC Evolutionary Biology, 9, 69. doi:10.1186/1471-2148-969

Huang, K., Guo, S. T., Shattuck, M. R., Chen, S. T., Qi, X. G., Zhang, P., \& Li, B. G. (2015). A maximum-likelihood estimation of pairwise relatedness for autopolyploids. Heredity, 114, 133-142. doi:10.1038/hdy.2014.88

Jones, O. R., \& Wang, J. (2010). COLONY: a program for parentage and sibship inference from multilocus genotype data. Molecular Ecology Resources, 10, 551-555. doi:10.1111/j.1755-0998.2009.02787.x

Joron, M., Frezal, L., Jones, R. T., Chamberlain, N. L., Lee, S. F., Haag, C. R., . . . FfrenchConstant, R. H. (2011). Chromosomal rearrangements maintain a polymorphic supergene controlling butterfly mimicry. Nature, 477, 203-208. doi:10.1038/Nature10341

Jowers, M. J., Leniaud, L., Cerda, X., Alasaad, S., Caut, S., Amor, F., . . Boulay, R. R. (2013). Social and population structure in the ant Cataglyphis emmae. Plos One, 8. doi:10.1371/journal.pone.0072941

Kalinowski, S. T. (2004). Counting alleles with rarefaction: private alleles and hierarchical sampling designs. Conservation Genetics, 5, 539-543.

Kamvar, Z. N., Tabima, J. F., \& Grunwald, N. J. (2014). Poppr: an R package for genetic analysis of populations with clonal, partially clonal, and/or sexual reproduction. PeerJ, 2, e281. doi:10.7717/peerj.281

Keller, L. (1995). Social life: the paradox of multiple-queen colonies. Trends in Ecology \& Evolution, 10, 355-360.

Keller, L., \& Ross, K. G. (1998). Selfish genes: a green beard in the red fire ant. Nature, 394, 573-575.

Küpper, C., Stocks, M., Risse, J. E., dos Remedios, N., Farrell, L. L., Mcrae, S. B., . . Burke, T. (2016). A supergene determines highly divergent male reproductive morphs in the ruff. Nature Genetics, 48, 79-83. doi:10.1038/ng.3443

Lawson, L. P., Vander Meer, R. K., \& Shoemaker, D. (2012). Male reproductive fitness and queen polyandry are linked to variation in the supergene Gp-9 in the fire ant Solenopsis 
invicta. Proceedings of the Royal Society B-Biological Sciences, 279, 3217-3222. doi:10.1098/Rspb.2012.0315

Li, H., \& Durbin, R. (2009). Fast and accurate short read alignment with Burrows-Wheeler transform. Bioinformatics, 25, 1754-1760. doi:10.1093/bioinformatics/btp324

Li, J. H., Cocker, J. M., Wright, J., Webster, M. A., McMullan, M., Dyer, S., . . Gilmartin, P. M. (2016). Genetic architecture and evolution of the S locus supergene in Primula vulgaris. Nature Plants, 2.

Libbrecht, R., \& Kronauer, D. J. C. (2014). Convergent evolution: the genetics of queen number in ants. Current Biology, 24, R1083-R1085. doi:10.1016/J.Cub.2014.09.066

Llaurens, V., Whibley, A., \& Joron, M. (2017). Genetic architecture and balancing selection: the life and death of differentiated variants. Molecular Ecology, 26, 2430-2448. doi:10.1111/mec.14051

Loiselle, B. A., Sork, V. L., Nason, J., \& Graham, C. (1995). Spatial genetic structure of a tropical understory shrub, Psychotria officinalis (Rubiaceae). American Journal of Botany, 82, 1420-1425.

Meunier, J., \& Chapuisat, M. (2009). The determinants of queen size in a socially polymorphic ant. Journal of Evolutionary Biology, 22, 1906-1913. doi:10.1111/j.14209101.2009.01805.x

Miller, S. A., Dykes, D. D., \& Polesky, H. F. (1988). A simple salting out procedure for extracting DNA from human nucleated cells. Nucleic Acids Research, 16, 1215. doi:10.1093/nar/16.3.1215

Mullon, C., Keller, L., \& Lehmann, L. (2018). Social polymorphism is favoured by the coevolution of dispersal with social behaviour. Nature Ecology \& Evolution, 2, 132-140. doi:10.1038/s41559-017-0397-y

Nonacs, P. (1988). Queen number in colonies of social Hymenoptera as a kin-selected adaptation. Evolution, 42, 566-580.

Pamilo, P., Gertsch, P., Thorén, P., \& Seppä, P. (1997). Molecular population genetics of social insects. Annual Review of Ecology and Systematics, 28, 1-25.

Purcell, J., Brelsford, A., Wurm, Y., Perrin, N., \& Chapuisat, M. (2014). Convergent genetic architecture underlies social organization in ants. Current Biology, 24, 2728-2732. doi:10.1016/J.Cub.2014.09.071

Purcell, J., \& Chapuisat, M. (2013). Bidirectional shifts in colony queen number in a socially polymorphic ant population. Evolution, 67, 1169-1180. doi:10.1111/evo.12010

Purcell, J., Pellissier, L., \& Chapuisat, M. (2015). Social structure varies with elevation in an Alpine ant. Molecular Ecology, 24, 498-507. doi:10.1111/Mec.13042

Purcell, J., Zahnd, S., Athanasiades, A., Türler, R., Chapuisat, M., \& Brelsford, A. (2016). Ants exhibit asymmetric hybridization in a mosaic hybrid zone. Molecular Ecology, 25, 4866-4874 doi:10.1111/mec.13799

Ross, K. G. (2001). Molecular ecology of social behaviour: analyses of breeding systems and genetic structure. Molecular Ecology, 10, 265-284. 
Ross, K. G., \& Keller, L. (1995). Joint influence of gene flow and selection on a reproductively important genetic polymorphism in the fire ant Solenopsis invicta. American Naturalist, 146, 325-348.

Rosset, H., \& Chapuisat, M. (2006). Sex allocation conflict in ants: when the queen rules. Current Biology, 16, 328-331.

Rosset, H., \& Chapuisat, M. (2007). Alternative life-histories in a socially polymorphic ant. Evolutionary Ecology, 21, 577-588.

Schwander, T., Libbrecht, R., \& Keller, L. (2014). Supergenes and complex phenotypes. Current Biology, 24, R288-R294. doi:10.1016/J.Cub.2014.01.056

Shoemaker, D. D., \& Ross, K. G. (1996). Effects of social organization on gene flow in the fire ant Solenopsis invicta. Nature, 383, 613-616.

Slatkin, M. (1985). Gene flow in natural populations. Annual Review of Ecology and Systematics, 16, 393-340.

Sun, Y., Svedberg, J., Hiltunen, M., Corcoran, P., \& Johannesson, H. (2017). Large-scale suppression of recombination predates genomic rearrangements in Neurospora tetrasperma. Nature Communications, 8. doi:10.1038/s41467-017-01317-6

Sundström, L., Keller, L., \& Chapuisat, M. (2003). Inbreeding and sex-biased gene flow in the ant Formica exsecta. Evolution, 57, 1552-1561.

Sundström, L., Seppä, P., \& Pamilo, P. (2005). Genetic population structure and dispersal patterns in Formica ants - a review. Annales Zoologici Fennici, 42, 163-177.

Sutter, A., \& Lindholm, A. K. (2015). Detrimental effects of an autosomal selfish genetic element on sperm competitiveness in house mice. Proceedings of the Royal Society BBiological Sciences, 282. doi:10.1098/rspb.2015.0974

Thompson, M. J., \& Jiggins, C. D. (2014). Supergenes and their role in evolution. Heredity, 113, 1-8. doi:10.1038/hdy.2014.20

Timmermans, I., Grumiau, L., Hefetz, A., \& Aron, S. (2010). Mating system and population structure in the desert ant Cataglyphis livida. Insectes Sociaux, 57, 39-46. doi:10.1007/s00040-009-0048-7

Tuttle, E. M., Bergland, A. O., Korody, M. L., Brewer, M. S., Newhouse, D. J., Minx, P., . . . Balakrishnan, C. N. (2016). Divergence and functional degradation of a sex chromosome-like supergene. Current Biology, 26, 344-350. doi:10.1016/j.cub.2015.11.069

Wang, J., Wurm, Y., Nipitwattanaphon, M., Riba-Grognuz, O., Huang, Y. C., Shoemaker, D., \& Keller, L. (2013). A Y-like social chromosome causes alternative colony organization in fire ants. Nature, 493, 664-668. doi:10.1038/Nature11832

Wedell, N. (2013). The dynamic relationship between polyandry and selfish genetic elements. Philosophical Transactions of the Royal Society B: Biological Sciences, 368, 20120049. doi:10.1098/rstb.2012.0049 


\section{MOLECULAR ECOLOGY}

Supplemental Information for:

Asymmetric assortative mating and queen polyandry are linked to a supergene controlling ant social organization

Amaury Avril, Jessica Purcell, Alan Brelsford \& Michel Chapuisat

Table of Contents:

\begin{tabular}{|l|l|}
\hline Figure S1. Map of colonies & Page 1 \\
\hline Figure S2. Scheme of experiment & Page 2 \\
\hline
\end{tabular}

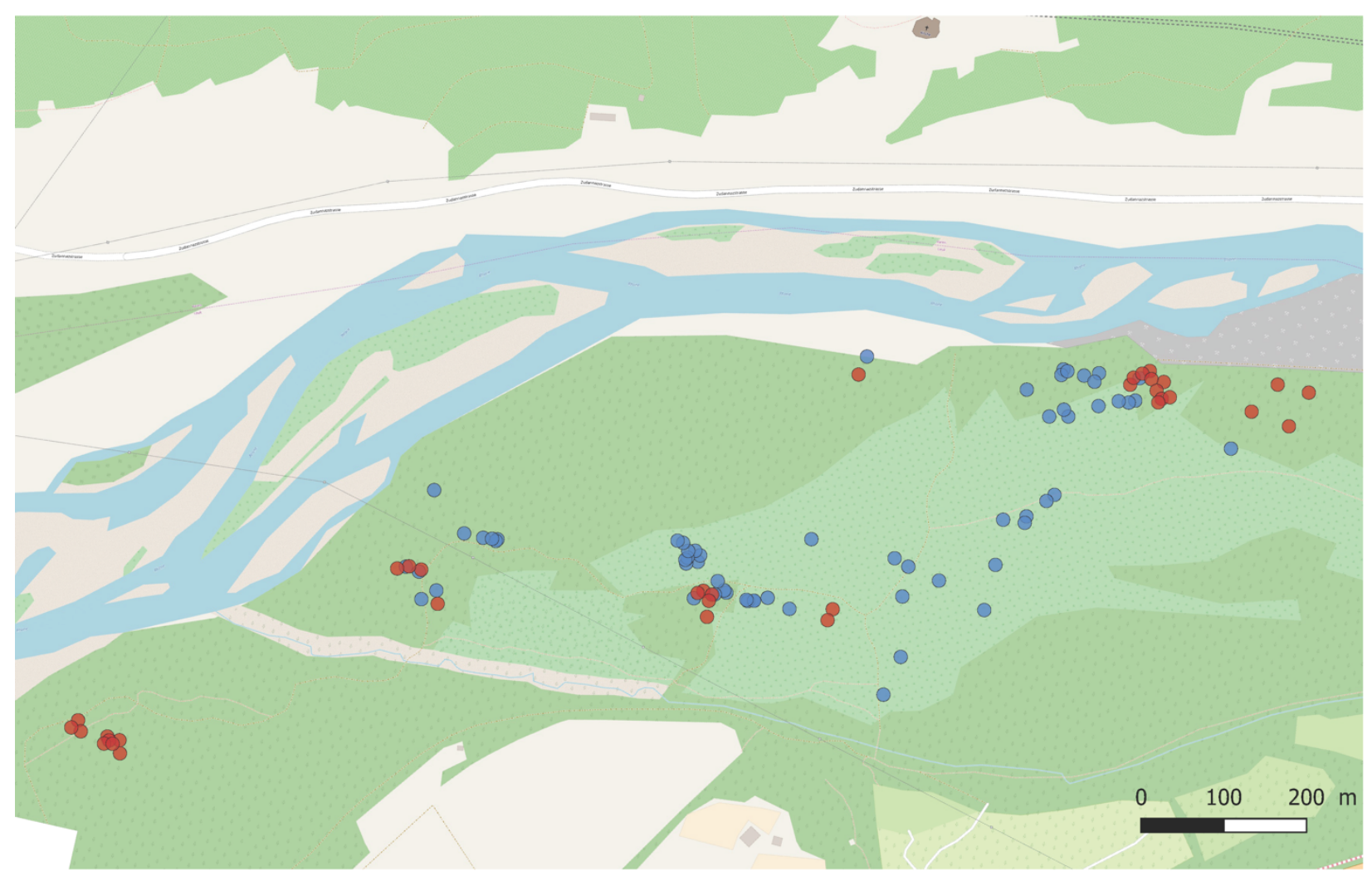

Figure S1. Map of monogynous (blue) and polygynous (red) colonies from which four workers per queen were collected for RAD-sequencing. 


\section{MOLECULAR ECOLOGY}

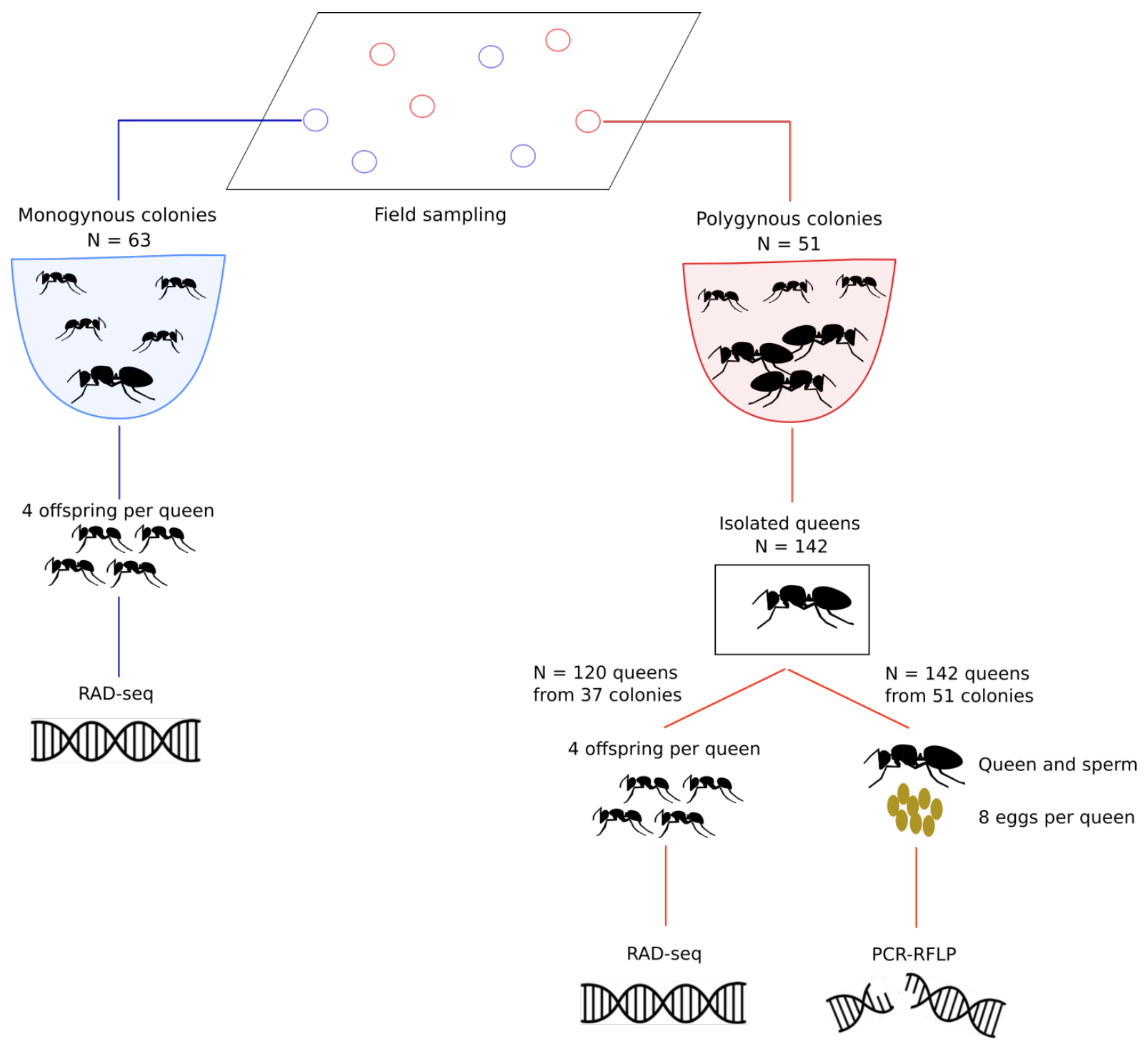

Figure S2. Scheme of the sampling and genotyping strategy. 